\title{
THE PATTERN OF LEPROSY IN THE GAMBIA, WEST AFRICA
}

\author{
by I. A. Susman, M.B., CH.B., D.T.м. \& H. \\ Medical Officer-in-charge, Gambia \\ Leprosy Control Project.
}

\section{Introduction}

The territory of the Gambia is situated in West Africa extending along both banks of the River Gambia to a distance of 11 to $24 \mathrm{~km}$. and for about $482 \mathrm{~km}$. from its mouth. It is an enclave of the Republic of Senegal and it has an area of about 10,360 sq. km. and a population of about a third of a million. Bathurst is the capital, situated on an island at the mouth of the river. The country consists of Bathurst and the small adjoining Kombo St. Mary Division (formerly known as the Colony) with a combined population of about 40,000 . The remainder of the country forms what was formerly known as the Protectorate and is divided into Western, Lower River, MacCarthy Island and Upper River Divisions. There are five main tribes of which the Mandingoes (or Mandinkas) predominate and these are spread fairly evenly throughout the territory on both banks, but especially concentrated in the Lower River Division. The Gambia, in common with most of West Africa, has a moist, tropical climate. The country has few natural resources and its economy is based almost entirely on the export of ground-nuts. The country has recently gained internal self-government and has appointed its first Premier.

The Gambia Leprosy Control Project first began to operate in August 1957. The work to date has been almost entirely field work, that is, on a mass out-patient treatment basis. A summary of the Annual Report for the Project for 1961 appeared in the July 1962 issue of the Leprosy Review.

Past surveys have shown the incidence of leprosy in the Gambia to be $2.5 \%$ (C. M. Ross, 1947) and 2.4\% (McFAdzeAN, 1954). During the present examination it was found that the incidence for the Bathurst area was 2.9 per mille and for the rest of the country 16.0 per mille, the overall incidence for the Gambia being 14.5 per mille. MallaC found the incidence for the up-river areas in 1960 to be 17.0 per mille. These latter figures, which are lower than the previous two surveys, are of course based on patients actually registered only and not on any intensive survey of whole populations so that the true incidence is likely to be somewhat higher than these figures suggest.

Between November 1961 and May 1962, a country-wide tour of all the leprosy clinics was made by the leprologist in order to examine, and record details of, every patient present, to verify 
diagnoses as far as possible and to make the first official discharges of those in whom the disease was either cured or arrested.

It must be pointed out that the disease was classified entirely on clinical grounds since neither bacteriological, immunological nor histological facilities were available. The disease was typed either Lepromatous or Tuberculoid or Dimorphous (that is, borderline cases, clinically showing features of both polar types) or Indeterminate. The latter diagnosis could be made only in cases which had very recently presented themselves being applied to those cases showing only one or very few nondescript macular lesions which were doubtless leprosy but which showed no other symptoms or signs to put them into one of the other categories. They are the lesions of uncertain prognosis and there is no nerve involvement. Tuberculoid leprosy was diagnosed in cases with very limited lesions, either in number or size, usually asymmetrical, since this is the type with a high degree of resistance (positive lepromin). If the lesions were very widespread, indicating a poor tissue response or defense, and if definite features of the pure Lepromatous type were not seen, the case was classified as Dimorphous. These latter lesions were, therefore, usually multiple (large and small lesions), widespread often symmetrical and of variable morphology; nerve thickening was present in many cases.

The ages of the patients in this survey must, of course, in by far the most of them, be approximate as most of them have no exact knowledge of their date of birth. The ages were judged mainly on physical development. 'Boys' and 'Girls' refer to patients up to and including 16 years of age.

Bearing in mind the above points, this paper is intended to give a fairly accurate overall picture of the types of leprosy and its disabilities occurring in the Gambia.

The disabilities (deformities and mutilations) were classified and graded according to the scheme suggested by the Second W.H.O. Expert Committee on Leprosy, which met in Geneva in August 1959. Grand Totals: The following shows the total numbers of leprosy patients registered, examined and discharged:

TABLE 1

\begin{tabular}{l|c|c|c|c|c|c}
\hline & $\begin{array}{c}\text { No. } \\
\text { registered }\end{array}$ & $\begin{array}{c}\% \text { of total } \\
\text { registered }\end{array}$ & $\begin{array}{c}\text { No. } \\
\text { examined }\end{array}$ & $\begin{array}{c}\% \text { of total } \\
\text { exumined }\end{array}$ & $\begin{array}{c}\text { No. } \\
\text { discharged }\end{array}$ & $\begin{array}{c}\% \\
\text { attendance }\end{array}$ \\
\hline Men & 1,199 & 28.33 & 790 & 27.93 & 137 & 65.88 \\
\hline Women & 1,447 & 34.19 & 968 & 34.22 & 236 & 66.89 \\
\hline Boys & 807 & 19.06 & 548 & 19.37 & 189 & 67.90 \\
\hline Girls & 780 & 18.43 & 523 & 18.49 & 166 & 67.05 \\
\hline Totals & 4,233 & & 2,829 & & 728 & 66.83 \\
\hline
\end{tabular}




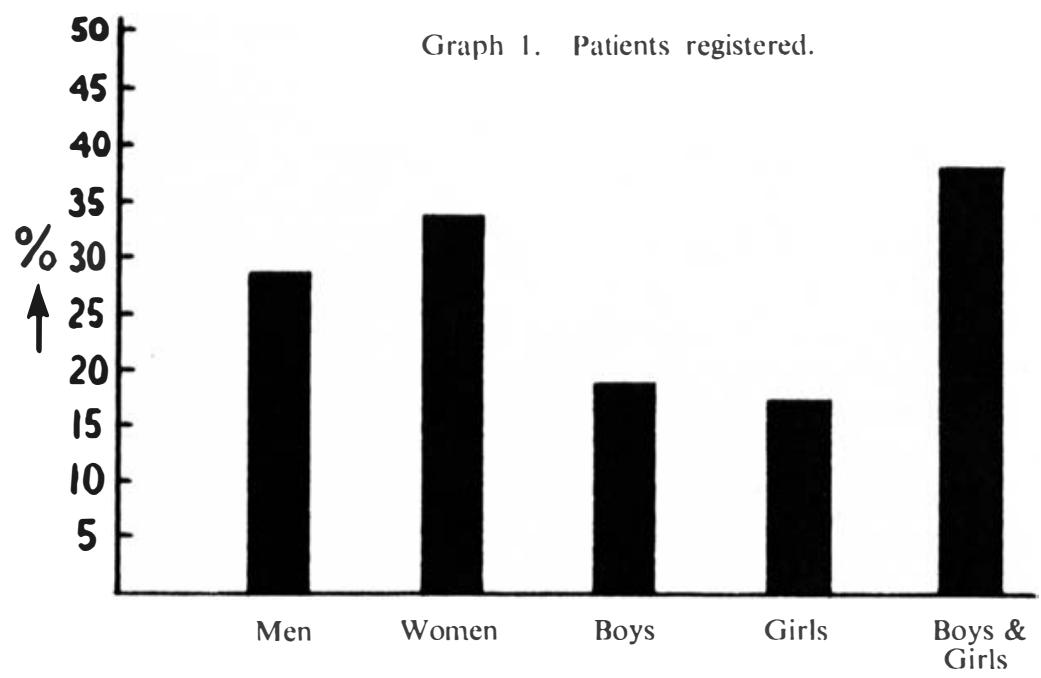

The totals for the various Divisions were as follows:

TABLE 2

\begin{tabular}{|c|c|c|c|c|c|c|}
\hline & Colony & $\begin{array}{l}\text { Western } \\
\text { Division }\end{array}$ & $\begin{array}{l}\text { Lower } \\
\text { River } \\
\text { Division }\end{array}$ & $\begin{array}{l}\text { McCarthy } \\
\text { Island } \\
\text { Division }\end{array}$ & $\begin{array}{l}\text { Upper } \\
\text { River } \\
\text { Division }\end{array}$ & Totals \\
\hline Population & $\begin{array}{c}40,000 \\
\text { (estimated) }\end{array}$ & 42,766 & 80,844 & 62,618 & 64,985 & 291,213 \\
\hline No. registered & 114 & 384 & 1,399 & 1,502 & 834 & 4,233 \\
\hline Incidence per 100 & 0.29 & 0.9 & 1.7 & 2.4 & 1.3 & 1.45 \\
\hline $\begin{array}{l}\% \text { of total } \\
\text { registered }\end{array}$ & 2.69 & 9.07 & 33.06 & 35.49 & 19.71 & - \\
\hline No. examined & 62 & 245 & 903 & 1,054 & 565 & 2,829 \\
\hline $\begin{array}{l}\% \text { of total } \\
\text { examined }\end{array}$ & 2.19 & 8.66 & 31.93 & 37.27 & 19.97 & - \\
\hline No. discharged & 8 & 70 & 189 & 285 & 176 & 728 \\
\hline $\begin{array}{l}\% \text { discharged of } \\
\text { No. examined }\end{array}$ & 12.90 & 28.57 & 20.93 & 27.04 & 31.16 & 25.73 \\
\hline$\%$ attendance & 54.39 & 63.81 & 64.54 & 70.18 & 67.74 & 66.83 \\
\hline
\end{tabular}

Types of Leprosy: It was found that $6.15 \%$ of the total number of patients examined had lepromatous leprosy, $6.26 \%$ dimorphous, $86.72 \%$ tuberculoid and $0.81 \%$ indeterminate.

Of the total lepromatous, $62.65 \%$ were men, $29.88 \%$ women, $4.6 \%$ boys and $2.87 \%$ girls.

Of the total dimorphous, $44.07 \%$ were men, $42.93 \%$ women, $8.47 \%$ boys and $4.52 \%$ girls.

Of the total tuberculoid, $24.52 \%$ were men, $33.85 \%$ women, $21.34 \%$ boys and $20.28 \%$ girls.

The indeterminate were a very small number, and were mostly diagnosed in the girls. (Vide Introduction.)

It was found that of the total number of patients examined. 
$47.31 \%$ were males $(27.93 \%$ men, $19.37 \%$ boys $)$ and $52.69 \%$ were females $(34.22 \%$ women, $18.49 \%$ girls $)$.

It is usually agreed that the disease has a higher incidence in men than in women. This is probably related to men's generally greater exposure to the disease by reason of their daily occupation outside the home, but this does not apply in the Gambia. Here, a great number of women work for long hours in the rice fields in addition to assisting with other farmwork.

Although, therefore, a larger proportion of women are under treatment, a slightly higher percentage of the children are boys. However, a larger proportion of the lepromatous patients are men and although there are more boys under treatment than girls, a higher percentage of the lepromatous children are boys. The females thus generally have the milder form of the disease.

\section{Age groups}

It was found that the numbers of males and females in each age group very closely corresponded except in the 21-30 years groups where the females formed nearly $60 \%$ of this group.

Of the total number examined $1.45 \%$ were in the estimated age group $0-5$ years, $13.04 \%$ were in $6-10$ years, $33.2 \%$ in $11-20$ years, $25.1 \%$ in $21-30$ years, $15.4 \%$ in $31-40$ years, $8.41 \%$ in $41-50$ years and $3.39 \%$ in the over 50 years group.

Thus, $47.69 \%$ of the patients examined were under 21 years of age, and $72.79 \%$ were under 31 years of age. Only $11.8 \%$ were over 40 .

\section{Age at onset of Disease}

All patients were asked how long it had been since they had first noticed some sign of the disease. This must again, be approximate since it depended on the patient's own memory or that of a relative.

It was found that $62.68 \%$ of all patients stated that they showed some sign of leprosy before they were 21 years of age. In fact, $35.46 \%$ were in their first ten years of life and $83.08 \%$ developed the first sign before 31 years, whereas only $5.87 \%$ said they first showed any sign after 40 years of age.

These figures confirm previous opinions that children and young adults up to the age of 21 years are most susceptible to the infection of leprosy, and it is very rare for adults, especially over 40 years, to become infected.

\section{Contacts}

All patients were asked if they had knowledge of any other person in their family or otherwise suffering from leprosy with whom they had been in contact at any time and from whom they believed they had contracted leprosy. 
Only 159 patients out of 2,829 examined, that is $5.62 \%$ of them, gave a positive answer. Such answers were obtained in about $11 \%$ of both the lepromatous and dimorphous patients and in about $5 \%$ only of the tuberculoids, and were as follows:

TABLE 3

\begin{tabular}{l|c|c}
\hline $\begin{array}{c}\text { Relationship given by } \\
\text { patient of affected contact }\end{array}$ & No. & $\begin{array}{c}\text { \% of total cases } \\
\text { attributable to each contact }\end{array}$ \\
\hline Brother & 40 & 25.16 \\
\hline Mother & 39 & 24.53 \\
\hline Sister & 29 & 18.24 \\
\hline Father & 20 & 12.58 \\
\hline Daughter & 7 & 4.40 \\
\hline Son & 5 & 3.15 \\
\hline Aunt & 4 & 2.52 \\
\hline Uncle & 4 & 2.52 \\
\hline Grandmother & 3 & 1.89 \\
\hline Cousin & 3 & 1.89 \\
\hline Husband & 3 & 1.89 \\
\hline Wife & 2 & 1.26 \\
\hline & 159 & \\
\hline
\end{tabular}

Thus, as far as could be ascertained from this small number of positive histories, about one quarter attributed their disease to contact with an infected brother and about one quarter with an infected mother. A sister accounted for less than one fifth, and a father for less than one seventh. Other relationships were in a very small minority.

\section{Disabilities}

It should be pointed out that there were actually 818 patients $(28.85 \%)$ recorded with disabilities but many of them had developed more than one type of lesion.

The figures given below of the various disabilities concern the actual numbers of these various types of lesion (of which there were 2,155 in all) so that patients with more than one disability will occur more than once in these figures.

Of this total of 818 patients, there were $143(17.52 \%)$ lepromatous, $108(13.23 \%)$ dimorphous and $567(69.25 \%)$ tuberculoid. This means that $82.19 \%$ of the total lepromatous (174), $61.01 \%$ of the total dimorphous (177) and $23.01 \%$ of the total tuberculoid $(2,455)$ 
showed one or more disabilities either of hands, feet, face or in gynaecomastia or leprotic laryngitis.

\section{Nerve Involvement. (A1-5, B1-5, C3)}

This refers to patients who showed any signs of neuritic complications of either hands, feet or face, that is, anaesthesia only, claw hand, muscular paralysis, absorption of digits, trophic ulceration or facial palsy.

Of the total patients $(2,829)$ examined, 776 , that is $27.43 \%$ (4.49\% lepromatous, $3.71 \%$ dimorphous, $19.23 \%$ tuberculoid) showed one or other, or several of these lesions. Of this number (776) with lesions, $51.93 \%$ were men, $41.36 \%$ women, $4.51 \%$ boys and $2.19 \%$ girls.

Of the grand total examined (2,829), $14.24 \%$ were men showing these nerve lesions, $11.34 \%$ were women, $1.24 \%$ boys and $0.61 \%$ girls.

The lepromatous formed $16.36 \%$ of the 776 patients thus affected, the dimorphous $13.53 \%$ and the tuberculoid $70.11 \%$.

Furthermore, it was seen that of the 174 lepromatous patients, 127 showed nerve lesions, that is $73 \%$, whereas of the 177 dimorphous cases $59.32 \%$ (105) showed nerve involvement and only $22.16 \%(544)$ of the tuberculoid cases $(2,455)$ were similarly complicated.

These latter figures do not seem to agree with the usual observation that nerve lesions are more common in tuberculoid than in lepromatous leprosy. However, this fallacy was apparently due to the fact that a very high percentage of the lepromatous cases were in the later stages of the disease, as shown by the following table:

TABLE 4

\begin{tabular}{c|c}
\hline $\begin{array}{c}\text { No. of years of } \\
\text { progress of disease }\end{array}$ & $\begin{array}{c}\text { No. of patients } \\
\text { (lepromatous) }\end{array}$ \\
\hline $0-2$ & 10 \\
$3-5$ & 29 \\
$6-9$ & 66 \\
$10-19$ & 61 \\
$20+$ & 8 \\
\hline & 174 \\
\hline
\end{tabular}

\section{Anaesthesia to pain, of hands (A1)}

This was recorded where there was anaesthesia only, as obtained from the patient's own history, and where there was no other lesion present. Anaesthesia was, of course, usually present in those cases below recorded as grades $2-5$ in both the hands and feet (A and B).

Eighty-six patients (3.04\%) gave this history of absence of pain 
sensation in their hands, $45(52.32 \%)$ were men, $37(43.02 \%)$ women, $1(1.16 \%)$ boy and $3(3.5 \%)$ girls.

Eighteen were lepromatous ( $10.35 \%$ of this type), 9 dimorphous $(5.08 \%)$ and 59 tuberculoid $(2.4 \%)$.

Claw Hand-mobile (A2)

This deformity is due to involvement of the ulnar or median nerve or both, the former usually above the elbow and the latter above the wrist.

In this series, the deformity was noted in patients who also had a useful thumb and in whom the hand was not stiff in the clawed position.

One hundred and thirty-nine patients $(4.91 \%)$ had this deformity, of whom $70(50.36 \%)$ were men, $43(30.94 \%)$ women, $19(13.68 \%)$ boys and $7(5.04 \%)$ girls.

They were composed of $13.79 \%$ of the lepromatous patients, $11.87 \%$ of the dimorphous and $3.83 \%$ of the tuberculoid.

Intrinsic paralysis involving fingers and thumb, or fingers only but with contracture (A3)

This degree of deformity was shown, either uni or bilaterally, in 147 patients, that is, $5.2 \%$ of the total examined. Of this number, $61.22 \%$ were men, $34.02 \%$ women, $3.4 \%$ boys and $1.36 \%$ girls. Amongst them, there were 17 lepromatous patients forming $9.77 \%$ of the total lepromatous (174), 16 dimorphous forming 9.04\% of this type and 114 tuberculoid forming only $4.64 \%$ of the tuberculoids.

\section{Partial absorption of fingers, but with useful length remaining (A4)}

This occurred in 269 patients $(9.51 \%), 129(47.95 \%)$ of this number being men, $127(47.21 \%)$ women, 9 (3.34\%) boys and $4(1.49 \%)$ girls.

The lepromatous patients with this degree of mutilation were 46 in number ( $26.44 \%$ of the total lepromatous); 40 were dimorphous $(22.6 \%)$ and 183 were tuberculoid $(7.45 \%)$.

\section{Gross absorption of fingers - stumps only left (A5)}

Two hundred and twenty-seven $(8.02 \%)$ of all patients were thus affected. Of these, $131(57.72 \%)$ were men, 92 (40.53\%) women, $1(0.44 \%)$ boy, and $3(1.32 \%)$ girls.

The patients with this deformity included 39 lepromatous (22.42\% of this type), 29 dimorphous (16.39\%) and 159 tuberculoid $(6.48 \%)$.

\section{Anaesthesia to pain, of feet (B1)}

This was recorded where there was anaesthesia only, as obtained from the patients' own history, and where there was no other lesion present. 
Only 12 patients $(0.42 \%)$ gave this history of absence of pain sensation in their feet without any other disability.

Seven $(58.33 \%)$ were men, $4(33.34 \%)$ women, $1(8.33 \%)$ boy, and no girls.

Seven were lepromatous $(4.02 \%$ of this type), 1 dimorphous $(0.57 \%)$ and 4 tuberculoid $(0.16 \%)$.

\section{Ulceration of feet (B2)}

Ulcers of the feet-were recorded even if they were, at the time of examination, in a healed state.

$14.49 \%(410)$ of all patients examined had such present or past ulceration. Of this number, $54.39 \%$ were men, $41.46 \%$ women, $3.41 \%$ boys and $0.73 \%$ girls.

Of the total men (790) examined, $28.23 \%$ (223) showed foot ulceration; of the women (968), $17.56 \%$ (170); of the boys (548), $2.55 \%$ (14); and of the girls (523), only $0.57 \%$ (3).

The ulcers occurred more commonly bilaterally, and when unilaterally, more on the left foot than the right one.

Furthermore, the figures showed that of the lepromatous patients, $36.79 \%$ developed foot ulceration, whereas the corresponding figures for the dimorphous and tuberculoid cases were 32.76 and $11.73 \%$ respectively.

\section{Foot-drop (B3)}

Foot-drop, due to involvement of the external peroneal nerve, does not usually recover without adequate operative treatment. In this series of cases it was found in 132 patients out of 2,829 , i.e., $4.67 \%$. It was also found that $5.17 \%$ (9) of the lepromatous patients (174) had either uni- or bi-lateral foot drop, $10.15 \%$ (18) in the case of dimorphous types (177), and $4.28 \%$.(105) of the tuberculoid types $(2,455)$.

Of the men examined (790), $12.53 \%$ (99) showed this deformity, of the women (968), 3.1\% (30) and of the boys (548), $0.55 \%$ (3), but there were no girls (523) affected.

The men formed $74.99 \%$ of the total number with foot-drop, the women $22.73 \%$ and the boys $2.27 \%$.

\section{Partial absorption of foot (up to one-third of surface area of sole lost) (B4)}

This deformity was nearly three times more common than foot-drop. It occurred in $11.84 \%$ of the patients ( 9 lepromatous, 18 dimorphous and 105 tuberculoid).

Again, a higher percentage of the lepromatous patients showed this type of mutilation than the other groups. In fact, it occurred in $34.49 \%$ of lepromatous cases, in $25.59 \%$ of dimorphous and in only $9.33 \%$ of the tuberculoid. Also men suffered more than women, 
and boys more than the girls - the figures being, $21.52 \%$ of the men, $15.91 \%$ of the women, $1.28 \%$ of the boys and $0.76 \%$ of the girls.

Of the total number with this deformity $50.75 \%$ were men, $45.97 \%$ women, $2.1 \%$ boys and $1.2 \%$ girls.

\section{Gross absorption of foot (more than one-third of foot lost) (B5)}

Only 39 men and 11 women showed this degree of mutilation.

Twenty-seven had this deformity in both feet.

Of these $50(1.77 \%)$ patients $(78 \%$ men, $22 \%$ women) with gross absorption of foot, 8 were lepromatous, representing $4.6 \%$ of this type; 5 dimorphous, representing $2.8 \%$ of this type and 37 tuberculoid, representing $1.5 \%$ only of all the tuberculoid cases.

Permanent mark or stigma of leprosy not amounting to ugliness (e.g., loss of eyebrows, deformity of the ear) (C1)

This was recorded in $47(1.66 \%)$ patients, of whom $27(57.45 \%)$ were men, $18(38.3 \%)$ women, $1(2.13 \%)$ boy and $1(2.13 \%)$ girl.

Forty-five were lepromatous ( $25.86 \%$ of this type), 1 was dimorphous $(0.56 \%)$ and 1 was tuberculoid $(0.04 \%)$.

\section{Collapsed nose (C2)}

Forty-seven patients (1.66\%), of whom $36(76.6 \%)$ were men and $11(23.4 \%)$ women, had a collapsed nose. No boys or girls showed this deformity.

Forty-two were of lepromatous type $(24.14 \%$ of the total lepromatous), 1 was dimorphous $(0.56 \%)$ and 4 were tuberculoid $(0.16 \%)$.

\section{Lagophthalmos (C3)}

Out of the 2,829 patients examined, 174 (6.15\%) had either uni- or bi-lateral lagophthalmos, 113 being of the bilateral type. $112(64.37 \%)$ were men, $58(38.34 \%)$ women and $4(2.3 \%)$ girls. There were no boys with lagophthalmos.

Twenty-eight were lepromatous ( $16.1 \%$ of this type), 22 dimorphous $(12.43 \%)$ and 124 tuberculoid $(5.05 \%)$.

Loss of vision in one eye or dimness of vision both eyes (able to count fingers) (C4)

Sixty-two $(2.19 \%)$ patients had this disability. Thirty-six $(58.06 \%)$ were men, $24(38.71 \%)$ women, and $2(3.23 \%)$ boys. There were no girls with this affliction of the eyes. Out of these 62 patients, 44 were actually blind in one eye and $18 \mathrm{had}$ the dimness in both eyes.

Eleven were lepromatous $(6.32 \%$ of lepromatous patients), 5 were dimorphous $(2.83 \%)$ and 46 tuberculoid (1.87\%).

\section{Blindness (both eyes) (C5)}

Only $2(0.07 \%)$ patients were completely blind. Both were women, one being of the dimorphous type and the other tuberculoid. 


\section{Gynaecomastia (D1)}

Fourteen men (ages 20-45 years) and 1 boy (aged 14 years) had this deformity, that is, $7.14 \%$ of the total lepromatous and dimorphous men and boys, 12 were bilateral.

Twelve were lepromatous $(10.26 \%$ of lepromatous men and boys), 3 were dimorphous $(3.23 \%)$.

\section{Laryngitis (D2)}

One lepromatous woman presented with this disability $0.04 \%$ of the total patients examined.

Of the 174 patients with lagophthalmos, only 11 showed, in addition, either blindness in one or both eyes or dimness of vision both eyes, as follows:

$\begin{array}{cclll}\text { 1. } & \text { W. } & \text { Tub. } & \text { Bilateral Lagophthalmos } & + \text { Bilateral Dimness } \\ \text { 2. } & \text { M. } & \text { Tub. } & \text { Bilateral Lagophthalmos } & + \text { Left Blindness } \\ \text { 3. } & \text { W. } & \text { Dim. } & \text { Bilateral Lagophthalmos } & + \text { Bilateral Blindness } \\ \text { 4. } & \text { M. } & \text { Dim. } & \text { Bilateral Lagophthalmos } & + \text { Right Blindness } \\ \text { 5. } & \text { M. } & \text { Tub. } & \text { Bilateral Lagophthalmos } & + \text { Right Blindness } \\ \text { 6. } & \text { M. } & \text { Lep. } & \text { Bilateral Lagophthalmos } & + \text { Right Blindness } \\ \text { 7. } & \text { M. } & \text { Tub. } & \text { Left Lagophthalmos } & + \text { Right Blindness } \\ \text { 8. } & \text { M. } & \text { Tub. } & \text { Left Lagophthalmos } & + \text { Right Blindness } \\ \text { 9. } & \text { M. } & \text { Tub. } & \text { Bilateral Lagophthalmos } & + \text { Left Blindness } \\ \text { 10. } & \text { M. } & \text { Tub. } & \text { Right Lagophthalmos } & \text { + Right Blindness } \\ \text { 11. } & \text { M. } & \text { Tub. } & \text { Bilateral Lagophthalmos } & \text { + Right Blindness }\end{array}$

Therefore, 163 patients had lagophthalmos without any affection of the eye itself, and 53 patients had blindness or dimness as above but without lagophthalmos.

\section{Summary of Disabilities in the three types of Leprosy}

The disabilities occurred on average 2.46 per lepromatous patient, 1.55 per dimorphous patient and 0.59 per tuberculoid patient. In nearly every type of disability a higher percentage of the lepromatous patients suffered than dimorphous and a higher percentage of the latter type than the tuberculoid cases. Hence, although a much larger number of disabled were of the tuberculoid type, they actually formed a much smaller percentage of the tuberculoids compared with the percentage of disabled amongst the other two types. As already explained, a very high percentage of the lepromatous cases were in the later stages of the disease (Table 4).

It was also found that a higher percentage of men $(53.74 \%)$ than women $(35.25 \%)$ suffered disabilities. Also $6.92 \%$ of the boys were affected as against $3.33 \%$ of the girls.

(These figures do not include indeterminate patients (23) for reasons explained at the beginning of this paper, nor one lepromatous male who had bilateral gynaecomastia only.)

Of the total lepromatous (174) examined, $142(82,19 \%)$; of the dimorphous (177), $108(61.01 \%)$; and of the tuberculoid $(2,455)$, $567(23.05 \%)$ had one or more disabilities. 
Combined disabilities of hands and feet were the most common $(28.77 \%)$, followed by those of the hands alone $(25.34 \%)$ and then those of hands, feet and face $(24.97 \%)$. Less common were disabilities of feet only $(7.83 \%)$, face only $(6.24 \%)$, hands and face $(5.51 \%)$ and least common, feet and face $(1.35 \%)$.

From the statistics drawn up to show the relationship of the side of the body to the disabled organ in the various sexes and age groups, the following points were deduced:

Hand disabilities were almost equally common on the right side $(17.84 \%)$ as on the left $(18.28 \%)$ in the men, and only slightly more common on the right $(18.62 \%)$ than on the left $(16.33 \%)$ in women.

In the men, $63.87 \%$ of the hand disabilities were bilateral; in the women, $65.04 \%$.

Feet disabilities were more common on the left $(20.63 \%)$ than on the right $(18.03 \%)$ in men, and also in women $(20.05 \%$ left $/ 15.99 \%$ right).

In men, the bilateral feet disabilities formed $61.34 \%$, and in women $63.96 \%$.

Facial deformities were more common on the right $(23.43 \%)$ than on the left $(13.14 \%)$ in men, and similarly in women $(26 \%$ right $/ 12 \%$ left).

In the men, the bilateral facial deformities formed $63.43 \%$ and in women $62 \%$.

Gynaecomastia occurred on the left $(20 \%)$ in 2 men and in 1 boy, and bilaterally $(80 \%)$ in 12 men.

Thus, from these figures it can be seen that $60-65 \%$ of hand, feet and facial disabilities were bilateral in both men and women. Furthermore, there was not a very marked difference in the incidence of right and left-sided deformities in the hands and feet in both adult sexes, that is, approximately $15-20 \%$ occurred unilaterally.

In the case of facial stigma, unilateral blindness, and lagophthalmos, these were twice as common on the right $(23-26 \%)$ in both men and women than on the left side (12-13\%).

As there were only small numbers of boys and girls showing disabilities, a comparison is not attempted.

\section{Summary and Conclusions}

1. This paper is an attempt to show, from an examination of as many leprosy patients as was possible at the time, the distribution of leprosy throughout the various divisions of the Gambia.

2. The diagnosis of the disease was entirely clinical and was divided into the two main polar types, lepromatous and tuberculoid, plus the dimorphous type and a few indeterminate cases (where these were seen very early and were, in actual effect, leprosy but indeterminate of type). 
3. The occurrence of leprosy in the various sexes and age groups has been analysed and some conclusion reached regarding the age of onset of the disease and the relationship of certain cases to contacts (obtained from actual histories).

4. Disabilities of hands, feet and face and also gynaecomastia and leprotic laryngitis were recorded and have been analysed according to their occurrence in the various types of the disease and in the various sexes and ages.

5. It can be seen that leprosy appears to have a high incidence (more than 10 per mille) in the Gambia. This high total incidence but rather low lepromatous rate $(6 \%)$ is an indication that the disease is serious from a public health point of view, since it indicates that there must exist every opportunity for the spread of the disease even from this small number of contagious cases. The stigma attached to leprosy in the Gambia is very slight compared to that in most other countries.

6. The high childhood rate $(38 \%)$ also indicates the favourability of circumstances to the spread of the disease.

7. The combination of this low lepromatous rate and high child rate may be some indication that leprosy is not a diminishing disease in the Gambia.

8. Such a widespread and disabling disease as leprosy in the Gambia, especially amongst the active working population (children and young adults), must have a hampering and deleterious effect on the agricultural development of the country. Since agriculture is the mainstay of the economy of the country, then it must be logical to assume that this disease must also affect the country's economy and requires, therefore, urgent priority for its eradication.

\section{Acknowledgement}

I am grateful to the Director of Medical Services, Dr. S. H. O. Jones, C.B.E., for kind permission to publish this paper.

\section{References}

Cochrane, R. G., Leprosy in Theory and Practice (1959, Bristol. John Wright \& Son). p. 58 et seq.; p. 65 et seq.

Diwan, V. S., A Survey of Deformities in Leprosy. (1962). Lep. Review, 33, 4, $255-262$.

Duarte, Do Pateo and Lima, Solarno. (1936). Da frequencia da lepra nos focos familiares estudio epidemiologica. Rev. Bras. Leprol. 4. No. espeo. 241-259.

Mallac, M. J., Aspects of Leprosy Control in the Gambia, B.W.A. (A Two-Year Assessment). (1960), Lep. Review, 31, 1, 12-18.

McFadzean, J. A. ANd McCourt, J. F., Leprosy in the Gambia, West Africa (April 1955), Lep. Review, 26, 2, 57-64.

oss, C. M., Report on a Sample Survey of the Gambia, 1947. Government Printer, Bathurst.

SPICKETT, S. G., Genetics and Epidemiology of Leprosy. (1962), Lep. Review, $33,2,76-93$ and $33,3,173-181$.

Susman, I. A., The Gambia Leprosy Control Project. Summary of Annual Repotr for 1961. (1962), Lep. Review, 33, 3, 211-216. 